\title{
Molecular perovskite high-energetic materials
}

\author{
Shao-Li Chen, Zi-Run Yang, Bin-Jie Wang, Yu Shang, Lin-Ying Sun, Chun-Ting He, \\ Hao-Long Zhou, Wei-Xiong Zhang ${ }^{*}$ and Xiao-Ming Chen ${ }^{*}$
}

Since the black powder, the first known explosive, was discovered by ancient Chinese in the seventh century, people have been finding powerful, stable, reliable and low-cost energetic materials for military equipment and civil industry. To obtain a better explosive performance, an efficient strategy is to load unstable chemical bonds [1-3], as well as to combine fuel with oxidizer components in a proper ratio for achieving sufficient combustion and rapid detonation [4-6]. An effective way is to incorporate fuel and oxidizer properties into a single molecule [7], as demonstrated by a series of classical organic nitro group/nitrogen-rich molecules, such as trinitrotoluene (TNT), pentaerythritol tetranitrate (PETN), cyclotrimethylene trinitramine (RDX), cyclotetramethylene tetranitramine (HMX), hexanitrohexaazaisowurtzitane (CL-20) and octanitrocubane (ONC) (Fig. S1). Loading more nitro groups and higher structural tension into a single molecule does improve explosive performance, but usually leads to complicated and not cost-effective synthetic procedures. By a trade-off of detonation performance and cost, HMX is regarded as the best military high-energetic explosives nowadays [7], although it is neither the most powerful one nor the cheapest one.

Parallel to the intensive studies on molecule engineering on the backbone of nitrogen-rich organic energetic molecules [8,9], the exploration of advanced energetic materials extends to the crystal engineering on their energetic co-crystals [10-13], energetic salts [14-20], as well as coordination polymers or metal-organic frameworks [21-27]. The essential strategy is to control the intermolecular packing/linkage of the energetic organic fuel and oxidizer components in crystals by non-covalent interactions to modify/enhance the explosive performance and/or to reduce the sensitivity to a practicable level. However, for a specific energetic molecular component, it is highly challenging to predict/engineer the crystal structure of its co-crystals, salts, or metal-organic frameworks [10], and the examples with good detonation performance, high stability and low cost are still scarce.

Here we present a promising solution, i.e., assembly of both low-cost organic fuel and oxidizer components into a closely packed, high-symmetry ternary compounds (vide infra), to achieve advanced energetic materials with a nice combination of high explosive power, high stability, and low cost. The presented materials belong to the so-called molecular perovskites [28] with a general formula of $\mathrm{ABX}_{3}$, which topologically mimic the cubic structure of the very well-known inorganic perovskites, the simplest high-symmetry structure for ternary compounds, but have at least one organic molecular component (usually A component). Recently, molecular perovskites have attracted growing attention, as illustrated by the extensive studies on methyl-ammonium lead iodide for high performance solar cells [29-32], and the phase transitions together with the relevant switching physical properties [33-35]. In the course of our investigation on relevant molecular perovskites [36], we discovered that, the well-known, low-cost oxidative perchlorate anion as X component, and compatible fuel organic cation as A component, can be easily assembled into molecular perovskites by one-pot reaction. Such simple synthetic approach led to a new class of highenergetic materials, $\left(\mathrm{H}_{2}\right.$ dabco $)\left[\mathrm{M}\left(\mathrm{ClO}_{4}\right)_{3}\right](\mathrm{DAPs}$, dabco $=$ 1,4-diazabicyclo[2.2.2] octane, $\mathrm{M}=\mathrm{Na}^{+}, \mathrm{K}^{+}, \mathrm{Rb}^{+}$and $\mathrm{NH}_{4}{ }^{+}$ for DAP-1, -2, -3 and -4 , respectively). This sort of lowcost materials not only has very different structures and components compared with the well-known high-energetic explosives, but also has a high detonation performance comparable to HMX and even CL-20, and a much higher thermal stability than them.

Non-hygroscopic powders of DAPs were obtained in a high yield $(>90 \%)$ by separating the precipitate product from the one-pot reactions of mixing aqueous solutions

MOE Key Laboratory of Bioinorganic and Synthetic Chemistry, School of Chemistry, Sun Yat-Sen University, Guangzhou 510275, China

*Corresponding authors (emails: zhangwx6@mail.sysu.edu.cn (Zhang WX); cxm@mail.sysu.edu.cn (Chen XM)) 


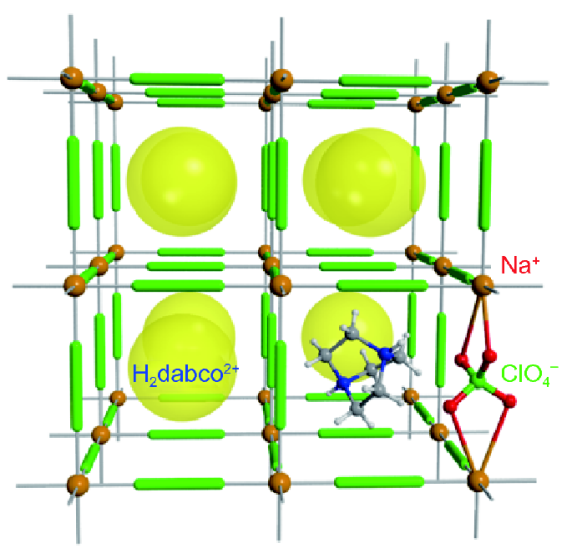

Figure 1 The perovskite structure of DAP-1. For clarity, only one $\mathrm{ClO}_{4}{ }^{-}$ bridge and one $\mathrm{H}_{2} \mathrm{dabco}^{2+}$ cation are shown, while the others are represented by green bars and yellow spheres, respectively.

of dabco, perchloric acid, and the corresponding perchlorate salt in a molar ratio of 1:2:1 at room temperature. The single-crystal X-ray diffraction at $232 \mathrm{~K}$ indicates that DAPs are isomorphous and crystallized in the cubic space group $\mathrm{Pa} \overline{3}$ (No. 206). As shown in Fig. 1, the structure of DAPs can be simply described as perovskite type, by regarding $\mathrm{H}_{2} \mathrm{dabco}^{2+}$ as A-site cation, $\mathrm{M}^{+}$as $\mathrm{B}$-site cation and $\mathrm{ClO}_{4}^{-}$as X-bridges. Each $\mathrm{M}^{+}$ion is surrounded by twelve oxygen atoms from six $\mathrm{ClO}_{4}^{-}$anions, while each $\mathrm{ClO}_{4}^{-}$anion bridges two $\mathrm{M}^{+}$ions, forming a three-dimensional anionic framework consisting of cages that are filled by $\mathrm{H}_{2} \mathrm{dabco}^{2+}$ cations. It is worth noting that, although DAP-1, -2 and -3 have B-site alkali ions with significantly different ion radius (coordination number = 12): $\mathrm{Na}^{+}(1.39 \AA)<\mathrm{K}^{+}(1.64 \AA)<\mathrm{Rb}^{+}(1.72 \AA)[37]$, their average $\mathrm{M} \cdots \mathrm{Cl}$ atomic distances vary in a narrow range of 3.551(1)-3.616(1) $\AA$ (Table S2). That is to say, the size of cage unit is almost independent of the $\mathrm{M}^{+}$ions, because the steric requirement of $\mathrm{H}_{2} \mathrm{dabco}^{2+}$ cations prevents the further contraction of anionic framework. In this sense, such perovskite structure leads to significant structural tension in DAPs, and the smaller $\mathrm{M}^{+}$ion is, the stronger structural tension is.

As shown in Fig. 2 and Table 1, the decomposition temperatures (onset) of DAPs range from 344 to $365^{\circ} \mathrm{C}$, which are much higher than those of the famous single explosives such as $\operatorname{HMX}\left(280^{\circ} \mathrm{C}\right)$, $\mathrm{RDX}\left(204^{\circ} \mathrm{C}\right)$, and CL$20\left(210^{\circ} \mathrm{C}\right)$. Such high thermal stability of DAPs should be ascribed to the steady covalent bonds of molecular components as well as the structure reinforcement by strong Coulombic interactions between the alternatelypacked cations and anions in the unique perovskite

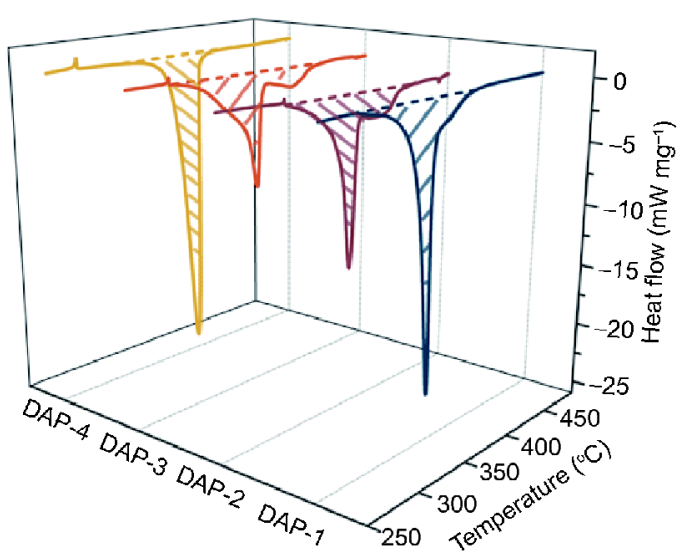

Figure 2 Differential scanning calorimetry graphs of DAPs.

Table 1 Thermal data of DAPs from DSC measurements

\begin{tabular}{cccc}
\hline Compounds & $T_{\mathrm{d}}^{\mathrm{a}}\left({ }^{\circ} \mathrm{C}\right)$ & $T_{\mathrm{p}}^{\mathrm{b}}\left({ }^{\circ} \mathrm{C}\right)$ & $Q_{\mathrm{DSC}}\left(\mathrm{kJ} \mathrm{g}^{-1}\right)$ \\
\hline DAP-1 & 344 & 361 & 4.40 \\
DAP-2 & 364 & 377 & 4.08 \\
DAP-3 & 352 & 369 & 3.80 \\
DAP-4 & 365 & 383 & 5.18 \\
\hline
\end{tabular}

a) The onset decomposition temperatures.b) The peak decomposition temperatures. c) The decomposition heat recorded by DSC.

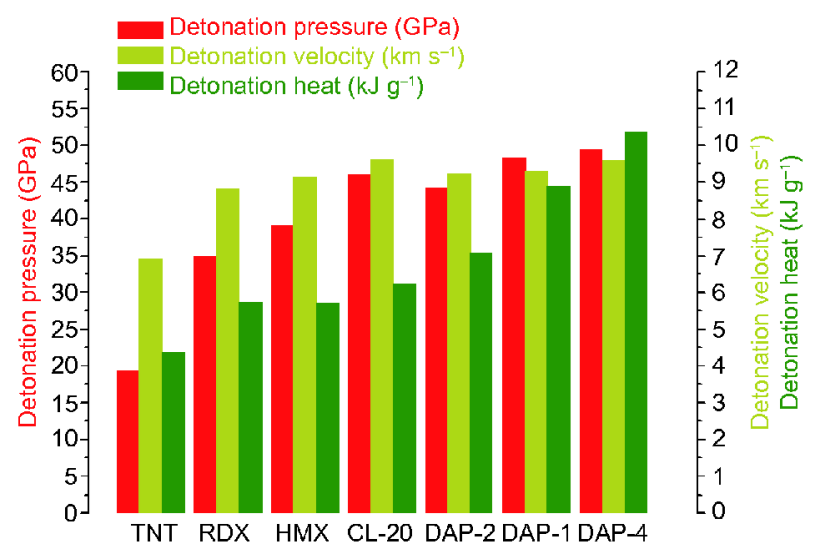

Figure 3 Bar chart representation of detonation parameters calculated by EXPLO5 V6.04.02, for DAP-1, DAP-2, DAP-4, and the well-known explosive materials including TNT, RDX, HMX and CL-20.

structure.

As evaluated by using EXPLO5 V6.04.02 program [38] (Fig. 3 and Table 2), DAP-1, -2 and -4 have excellent detonation performances superior to HMX and comparable to CL-20. Their detonation heats in a descending order are: $10.38 \mathrm{~kJ} \mathrm{~g}^{-1}$ (DAP-4) $>8.89 \mathrm{~kJ} \mathrm{~g}^{-1}(\mathrm{DAP}-1)>$ 
Table 2 Detonation properties of well-known explosives and DAPs

\begin{tabular}{|c|c|c|c|c|c|c|c|c|}
\hline Compound & $\rho^{\mathrm{a}}\left(\mathrm{g} \mathrm{cm}^{-3}\right)$ & $\begin{array}{c}\Delta H_{\mathrm{f}}^{\mathrm{b}} \\
\left.(\mathrm{kJ} \mathrm{mol})^{-1}\right)\end{array}$ & $\begin{array}{c}Q^{\mathrm{c}} \\
\left(\mathrm{kJ} \mathrm{g}^{-1}\right)\end{array}$ & $\begin{array}{c}D^{\mathrm{c}} \\
\left(\mathrm{km} \mathrm{s}^{-1}\right)\end{array}$ & $\begin{array}{c}P^{c} \\
(\mathrm{GPa})\end{array}$ & $\begin{array}{l}\text { IS } \\
(\mathrm{J})\end{array}$ & $\begin{array}{l}\text { FS } \\
(\mathrm{N})\end{array}$ & $\begin{array}{l}\mathrm{OB}^{\mathrm{e}} \\
(\%)\end{array}$ \\
\hline TNT & 1.65 & -59.3 & 4.36 & 6.915 & 19.4 & 15 & 353 & -24.7 \\
\hline RDX & 1.80 & 70.3 & 5.74 & 8.817 & 34.9 & 7.4 & 120 & 0 \\
\hline HMX & 1.91 & 74.8 & 5.72 & 9.152 & 39.1 & 7.5 & 112 & 0 \\
\hline CL-20 & 2.04 & 397.8 & 6.22 & 9.598 & 45.9 & 4 & 48 & 11.0 \\
\hline DAP-1 & $2.02^{\mathrm{a}}$ & $1013.7^{\mathrm{b}}$ & 8.89 & 9.306 & 48.3 & 17 & 36 & 0 \\
\hline DAP-2 & $2.04^{\mathrm{a}}$ & $247.3^{\mathrm{b}}$ & 7.09 & 9.224 & 44.2 & 16 & 42 & 0 \\
\hline DAP $-3^{d}$ & $2.16^{\mathrm{a}}$ & I & I & I & I & 22 & 28 & 0 \\
\hline DAP-4 & $1.87^{\mathrm{a}}$ & $1904.2^{\mathrm{b}}$ & 10.38 & 9.588 & 49.4 & 23 & 36 & -5.6 \\
\hline
\end{tabular}

a) $\rho$ is the density of powder sample measured by capillary powder X-ray diffraction at room temperature; b) $\Delta H_{\mathrm{f}}$ is the heat of formation calculated from heat of combustion tested by oxygen bomb; $c) Q$ is the heat of detonation, $D$ is the detonation velocity, and $P$ is the detonation pressure. The detonation parameters were calculated by EXPLO5 V6.04.02; d) since EXPLO5 doesn't cover rubidium element, the detonation parameters of DAP-3 could not to be calculated; e) oxygen balance based on $\mathrm{CO}$ for $\mathrm{C}_{a} \mathrm{H}_{b} \mathrm{~N}_{c} \mathrm{M}_{d} \mathrm{Cl}_{e} \mathrm{O}_{f}, \mathrm{M}$ as alkali metal ion, were calculated by: OB[\%] $=1600[f-a-(b-e+d) / 2] /$ $M_{W}$, where $M_{W}$ is molecular weight.

$7.09 \mathrm{~kJ} \mathrm{~g}^{-1}$ (DAP-2), and all are higher than those of classic high explosives such as RDX $\left(5.74 \mathrm{~kJ} \mathrm{~g}^{-1}\right)$, HMX $\left(5.72 \mathrm{~kJ} \mathrm{~g}^{-1}\right)$ and CL-20 $\left(6.22 \mathrm{~kJ} \mathrm{~g}^{-1}\right)$. The detonation velocities of DAPs are in range of $9.224-9.588 \mathrm{~km} \mathrm{~s}^{-1}$, higher than that of HMX $\left(9.152 \mathrm{~km} \mathrm{~s}^{-1}\right)$ and close to that of CL-20 $\left(9.598 \mathrm{~km} \mathrm{~s}^{-1}\right)$, meanwhile their detonation pressures (44.2-49.4 GPa) are much higher than that of HMX (39.1 GPa), and particularly, both of DAP-4 $(49.4 \mathrm{GPa})$ and DAP-1 $(48.3 \mathrm{GPa})$ are even higher than that of CL-20 (45.9 GPa).

It is worth noting that the large difference in denotation heats $\left(3,872-3,202=670 \mathrm{~kJ} \mathrm{~mol}^{-1}\right)$ between DAP-1 and DAP-2 is mainly ascribed to their large difference in combustion heats $\left(5,685-4,945=740 \mathrm{~kJ} \mathrm{~mol}^{-1}\right)$. Meanwhile, their combustion products only differ in metal chlorides, in which $\mathrm{NaCl}$ has an enthalpy of formation $\left(-411.1 \mathrm{~kJ} \mathrm{~mol}^{-1}\right)$ slightly higher than that of $\mathrm{KCl}$ $\left(-436.7 \mathrm{~kJ} \mathrm{~mol}^{-1}\right)$, and the smaller $\mathrm{Na}^{+}$ions lead to the stronger structural tension of the anionic framework in DAP-1 than that in DAP-2. These facts strongly imply that, the released detonation heats of DAPs do not just come from the breaking and recombination of covalent bonds during the denotation reaction, but also are notably contributed by the structural tension in the perovskite structure. Thus, such perovskite structure plays an important role in enhancing the dentation heat for DAPs.

For the metal-free member, i.e., DAP-4, it could be regarded as the modification of ammonium perchlorate (AP), the most-commonly-used oxidizing component in solid rocket propellants. The replacement of alkali metal ions by $\mathrm{NH}_{4}{ }^{+}$ions enables DAP-4 to give a much better denotation performance than the metal-contained mem-
Table 3 Specific impulse of well-known oxidizing agents, explosives and DAP-4

\begin{tabular}{cccccccc}
\hline $\begin{array}{c}\text { Com- } \\
\text { pound }\end{array}$ & AP & ADN & TNT & RDX & HMX & CL-20 & DAP-4 \\
\hline$I_{\mathrm{sp}}{ }^{\mathrm{a}}(\mathrm{s})$ & 157 & 202 & 206 & 267 & 266 & 272 & 344 \\
\hline
\end{tabular}

a) The specific impulses were calculated by EXPLO5 V6.04.02.

bers, due to the extra oxidation of ammonium to release more denotation heat and gas products. Moreover, the denotation of DAP-4 gives an extremely high calculated specific impulse $\left(I_{\mathrm{sp}}\right)$ value of $344 \mathrm{~s}$, much higher than those of RDX (267 s), HMX (266 s) and CL-20 (272 s) (Table 3). As an increase of about $10 \mathrm{~s}$ in $I_{\mathrm{sp}}$ can double the payload of a rocket [4], one could expect that DAP-4 may significantly improve the performance for the presently used propellants.

Distinguishing from the other high-energy-density materials which are mainly derived from nitrogen-rich heterocycles and their cations, DAPs present a new class of single explosives based on ternary compounds that are uniform versions of oxidants and fuels at molecular level, in which the size-matched fuel cations $\left(\mathrm{H}_{2} \mathrm{dabco}^{2+}\right)$ are tightly confined in the cubic cages composed of oxidative anions $\left(\mathrm{ClO}_{4}^{-}\right)$in a triple molar ratio. The design of molecular perovskite energetic materials retrospects the history of composite explosives from black powders to modern industrial emulsion explosives, at which pursuing better and better intimacy of oxidants and reductants is a direct means to achieve better detonation performance. But instead of making improvements of mechanical agitation, perovskite structure provides an alternative and dense packing of each fuel molecules with triple oxidant 
groups at molecular level for achieving the ultimate uniform in a single explosive, resulting in good oxygen balances same with (or close to) those of HMX and RDX, high densities, and eventually, excellent detonation properties. The steady covalent bonds of molecular components, together with the structural reinforcement by strong Coulombic interactions between the cations and anions in perovskite structure, achieved high thermal stability for DAPs, as well as an isotropic response to the external stimuli [39] by the cubic symmetry to achieve low impact sensivity (Table 2). In addition, different from their raw materials that are binary salts with serious hygroscopicity, DAPs are ternary ionic crystals without heavy-metal ions, and feature with non-hygroscopic, non-volatile, and non-weathering characteristics, which are beneficial for the storage and transportation.

Moreover, as demonstrated by DAPs with different Bsite cations, the molecular perovskites provide an opportunity to tailor the performances by taking the tunable/modifiable characteristics of the three components. In fact, we have recently found several analogues of DAPs, by replacing $\mathrm{H}_{2}$ dabco ${ }^{2+}$ with piperazine-1,4-diium cation on the A component, and/or replacing perchlorate with nitrate on the $\mathrm{X}$ component, and also some solid solutions of DAPs. A detailed study is now underway for these new materials. Regarding the diversities of the organic cations (especially lost-cost but high-calorific-value ones), oxidative anions and the high-symmetry crystal structure, the molecular design strategy illustrated by DAPs opens a new avenue for designing the advanced energetic materials for practical uses.

Received 31 December 2017; accepted 25 January 2018; published online 10 February 2018

1 Eremets MI, Gavriliuk AG, Trojan IA, et al. Single-bonded cubic form of nitrogen. Nat Mater, 2004, 3: 558-563

2 Zhang C, Sun C, Hu B, et al. Synthesis and characterization of the pentazolate anion cyclo- $\mathrm{N}_{5}{ }^{-}$in $\left(\mathrm{N}_{5}\right)_{6}\left(\mathrm{H}_{3} \mathrm{O}\right)_{3}\left(\mathrm{NH}_{4}\right)_{4} \mathrm{Cl}$. Science, 2017, 355: $374-376$

3 Xu Y, Wang Q, Shen C, et al. A series of energetic metal pentazolate hydrates. Nature, 2017, 549: 78-81

4 Bélanger-Chabot G, Rahm M, Haiges R, et al. Ammonia-(dinitramido)boranes: High-energy-density materials. Angew Chem Int Ed, 2015, 54: 11730-11734

5 Fischer D, Gottfried JL, Klapötke TM, et al. Synthesis and investigation of advanced energetic materials based on bispyrazolylmethanes. Angew Chem Int Ed, 2016, 55: 16132-16135

6 Zhang W, Zhang J, Deng M, et al. A promising high-energydensity material. Nat Commun, 2017, 8: 181

7 Agrawal JP. High Energy Materials: Propellants, Explosives and Pyrotechnics. Weinheim: Wiley-VCH Verlag GmBH \& Co. KGaA, 2010
8 Tang Y, Kumar D, Shreeve J'M. Balancing excellent performance and high thermal stability in a dinitropyrazole fused 1,2,3,4-tetrazine. J Am Chem Soc, 2017, 139: 13684-13687

9 Hermann TS, Karaghiosoff K, Klapötke TM, et al. Synthesis and characterization of 2,2'-dinitramino-5,5'-bi(1-oxa-3,4-diazole) and derivatives as economic and highly dense energetic materials. Chem Eur J, 2017, 23: 12087-12091

10 Bolton O, Matzger AJ. Improved stability and smart-material functionality realized in an energetic cocrystal. Angew Chem Int Ed, 2011, 50: 8960-8963

11 Landenberger KB, Bolton O, Matzger AJ. Energetic-energetic cocrystals of diacetone diperoxide (DADP): Dramatic and divergent sensitivity modifications via cocrystallization. J Am Chem Soc, 2015, 137: 5074-5079

12 Zhang J, Shreeve JM. Time for pairing: cocrystals as advanced energetic materials. CrystEngComm, 2016, 18: 6124-6133

13 Bennion JC, Siddiqi ZR, Matzger AJ. A melt castable energetic cocrystal. Chem Commun, 2017, 53: 6065-6068

14 Fischer N, Fischer D, Klapötke TM, et al. Pushing the limits of energetic materials-the synthesis and characterization of dihydroxylammonium 5,5'-bistetrazole-1,1'-diolate. J Mater Chem, 2012, 22: 20418-20422

15 Freis M, Klapötke TM, Stierstorfer J, et al. Di(1H-tetrazol-5-yl) methane as neutral ligand in energetic transition metal complexes. Inorg Chem, 2017, 56: 7936-7947

16 Tang Y, Gao H, Mitchell LA, et al. Syntheses and promising properties of dense energetic 5,5'-dinitramino-3,3'-azo-1,2,4-oxadiazole and its salts. Angew Chem Int Ed, 2016, 55: 3200-3203

17 Yin P, Zhang J, Mitchell LA, et al. 3,6-Dinitropyrazolo[4,3-c]pyrazole-based multipurpose energetic materials through versatile $\mathrm{N}$ functionalization strategies. Angew Chem Int Ed, 2016, 55: 1289512897

18 Tang Y, Mitchell LA, Imler GH, et al. Ammonia oxide as a building block for high-performance and insensitive energetic materials. Angew Chem Int Ed, 2017, 56: 5894-5898

19 Zhang L, Song KX, Zhang Z, et al. Insensitive ionic bio-energetic materials derived from amino acids. Sci Rep, 2017, 7: 12744

20 Liu W, Liu WL, Pang SP. Structures and properties of energetic cations in energetic salts. RSC Adv, 2017, 7: 3617-3627

21 Bushuyev OS, Brown P, Maiti A, et al. Ionic polymers as a new structural motif for high-energy-density materials. J Am Chem Soc, 2012, 134: 1422-1425

22 Li S, Wang Y, Qi C, et al. 3D energetic metal-organic frameworks: synthesis and properties of high energy materials. Angew Chem Int Ed, 2013, 52: 14031-14035

23 Zhang J, Du Y, Dong K, et al. Taming dinitramide anions within an energetic metal-organic framework: A new strategy for synthesis and tunable properties of high energy materials. Chem Mater, 2016, 28: 1472-1480

24 Zhang S, Yang Q, Liu X, et al. High-energy metal-organic frameworks (HE-MOFs): Synthesis, structure and energetic performance. Coord Chem Rev, 2016, 307: 292-312

25 Chen D, Jing D, Zhang Q, et al. Study of six green insensitive high energetic coordination polymers based on alkali/alkali-earth metals and 4,5-bis(tetrazol-5-yl)-2H-1,2,3-triazole. Chem Asian J, 2017, 12: 3141-3149

26 Wang $\mathrm{Q}$, Wang $\mathrm{S}$, Feng X, et al. A heat-resistant and energetic metal-organic framework assembled by chelating ligand. ACS Appl Mater Interfaces, 2017, 9: 37542-37547

27 Wang S, Wang Q, Feng X, et al. Explosives in the cage: Metal- 
organic frameworks for high-energy materials sensing and desensitization. Adv Mater, 2017, 29: 1701898

28 Boström HLB, Hill JA, Goodwin AL. Columnar shifts as symmetry-breaking degrees of freedom in molecular perovskites. Phys Chem Chem Phys, 2016, 18: 31881-31894

29 Sun L. Crystal crosslinking. Nat Chem, 2015, 7: 684-685

30 Liu T, Zhou Y, Hu Q, et al. Fabrication of compact and stable perovskite films with optimized precursor composition in the fastgrowing procedure. Sci China Mater, 2017, 60: 608-616

31 Ding J, Yan Q. Progress in organic-inorganic hybrid halide perovskite single crystal: growth techniques and applications. Sci China Mater, 2017, 60: 1063-1078

32 Xue $\mathrm{M}$, Zhou $\mathrm{H}, \mathrm{Xu} \mathrm{Y}$, et al. High-performance ultraviolet-visible tunable perovskite photodetector based on solar cell structure. Sci China Mater, 2017, 60: 407-414

33 Cheetham AK, Rao CNR. There's room in the middle. Science, 2007, 318: 58-59

34 Xu WJ, Du ZY, Zhang WX, et al. Structural phase transitions in perovskite compounds based on diatomic or multiatomic bridges. CrystEngComm, 2016, 18: 7915-7928

35 You YM, Liao WQ, Zhao D, et al. An organic-inorganic perovskite ferroelectric with large piezoelectric response. Science, 2017, 357: 306-309

36 Chen SL, Zhang WX, Chen XM. The $9^{\text {th }}$ National Conference in Inorganic Chemistry - B Coordination Chemistry. Nanchang, 2015

37 Hand Book of Chemistry and Physics. $84^{\text {th }}$ edition, Florida: CRC
Press, Taylor \& Francis Group, 2004

38 M. Sućeska, EXPLO5 6.04; Zagreb, Croatia, 2017

39 Feng G, Jiang X, Wei W, et al. High pressure behaviour and elastic properties of a dense inorganic-organic framework. Dalton Trans, 2016, 45: 4303-4308

Acknowledgements This work was supported by the National Natural Science Foundation of China (21290173 and 21722107). We thank Mr Xu JG and Prof Guo GC at Fujian Institute of Research on the Structure of Matter for some friction tests, and Prof Li W in Huazhong University of Science and Technology for valuable discussions. Sun Yat-Sen University authorized a China patent (ZL201610665880.3), and filed PCT patents related to this work.

Author contributions Zhang WX, Chen XM and Chen SL conceived the idea, designed the experiments and co-wrote the manuscript. Chen SL conducted synthetic experiments, calculations, and performed the DSC, TGA, PXRD measurements. Yang ZR, Wang BJ, Shang Y and Sun LY assisted the synthetic experiments. He CT assisted the calculations. Zhou HL performed the single-crystal XRD measurements. All authors discussed the results and commented on the manuscript.

Conflict of interest The authors declare that they have no conflict of interest.

Supplementary information Experimental details and supporting data are available in the online version of the paper. 

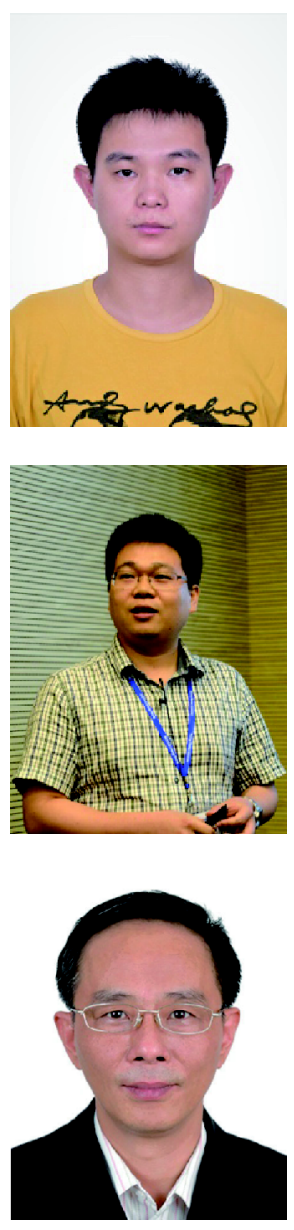

Shao-Li Chen was born in 1990. He is a PhD candidate of inorganic chemistry in Sun Yat-Sen University (SYSU). His research is focused on energetic salts.
Wei-Xiong Zhang obtained his BSc in 2004 and PhD in 2009 at SYSU, and was a JSPS postdoc at Tohoku University from 2010 to 2012. He joined SYSU as an associate professor in 2012. His current research interest is in synthesis and crystal engineering of functional coordination compounds.
Xiao-Ming Chen obtained his BSc in 1983 and MSc in 1986 from SYSU, and his PhD from Chinese University of Hong Kong in 1992. He then joined SYSU and became a professor in 1995. He was elected to CAS in 2009 and TWAS in 2013. His current research interest is focused on the synthesis and crystal engineering of functional metal complexes and coordination polymers.

\section{分子钙钛矿含能材料}

陈劯力, 杨子润, 王斌杰, 尚宇, 孙林颖, 何纯挺, 周浩龙, 张伟雄 ${ }^{*}$ 陈小明 ${ }^{*}$

摘要 设计合成兼具良好爆轰性能、高稳定性和低成本的含能化合物是发展实用含能材料的关键. 本文报道了一类新型分子钙钛矿含能 化合物, 它们可以通过使用低成本原料经简单一锅反应制备. 作为氧化组分的高氯酸根阴离子和作为燃料组分的还原性有机阳离子交替 紧密堆积于钲钛矿结构中, 使该类化合物不仅有比目前军用含能炸药(例如RDX和HMX)更优异的爆炸性能, 而且有更高的稳定性; 其中无 金属组分的分子钙钛矿含能化合物具有与CL-20相当的爆炸性能以及更高的比冲(约 344 秒). 这种将低成本有机燃料组分和氧化剂组分组 装在高对称性三元晶体结构的分子组装策略为设计有实用前景的含能材料提供了新思路. 